\title{
Assessment of the capacity of vehicle cabin air inlet filters to reduce diesel exhaust-induced symptoms in human volunteers
}

\author{
Ala Muala ${ }^{1}$, Maria Sehlstedt ${ }^{1}$, Anne Bion², Camilla Österlund ${ }^{1,3}$, Jenny A Bosson ${ }^{1}$, Annelie F Behndig ${ }^{1}$, \\ Jamshid Pourazar ${ }^{1}$, Anders Bucht ${ }^{1,3}$, Christoffer Boman ${ }^{4}$, lan S Mudway ${ }^{5}$, Jeremy P Langrish ${ }^{6}$, Stephane Couderc ${ }^{2}$, \\ Anders Blomberg ${ }^{1}$ and Thomas Sandström ${ }^{1 *}$
}

\begin{abstract}
Background: Exposure to particulate matter (PM) air pollution especially derived from traffic is associated with increases in cardiorespiratory morbidity and mortality. In this study, we evaluated the ability of novel vehicle cabin air inlet filters to reduce diesel exhaust (DE)-induced symptoms and markers of inflammation in human subjects.

Methods: Thirty healthy subjects participated in a randomized double-blind controlled crossover study where they were exposed to filtered air, unfiltered DE and DE filtered through two selected particle filters, one with and one without active charcoal. Exposures lasted for one hour. Symptoms were assessed before and during exposures and lung function was measured before and after each exposure, with inflammation assessed in peripheral blood five hours after exposures. In parallel, PM were collected from unfiltered and filtered DE and assessed for their capacity to drive damaging oxidation reactions in a cell-free model, or promote inflammation in A549 cells.

Results: The standard particle filter employed in this study reduced $\mathrm{PM}_{10}$ mass concentrations within the exposure chamber by $46 \%$, further reduced to $74 \%$ by the inclusion of an active charcoal component. In addition use of the active charcoal filter was associated by a $75 \%$ and $50 \%$ reduction in $\mathrm{NO}_{2}$ and hydrocarbon concentrations, respectively. As expected, subjects reported more subjective symptoms after exposure to unfiltered DE compared to filtered air, which was significantly reduced by the filter with an active charcoal component. There were no significant changes in lung function after exposures. Similarly diesel exhaust did not elicit significant increases in any of the inflammatory markers examined in the peripheral blood samples 5 hour post-exposure. Whilst the filters reduced chamber particle concentrations, the oxidative activity of the particles themselves, did not change following filtration with either filter. In contrast, diesel exhaust PM passed through the active charcoal combination filter appeared less inflammatory to A549 cells.
\end{abstract}

Conclusions: A cabin air inlet particle filter including an active charcoal component was highly effective in reducing both DE particulate and gaseous components, with reduced exhaust-induced symptoms in healthy volunteers. These data demonstrate the effectiveness of cabin filters to protect subjects travelling in vehicles from diesel exhaust emissions.

\footnotetext{
* Correspondence: thomas.sandstrom@lung.umu.se

${ }^{1}$ Department of Public Health and Clinical Medicine, Division of Medicine, Umeå University, Umeå, Sweden

Full list of author information is available at the end of the article
} 


\section{Introduction}

It is well documented that exposure to air pollution causes adverse cardiorespiratory health effects and a large number of epidemiological studies have documented the relationship between increased fine particulate air pollution and high mortality rates [1-3]. Exposure to traffic-derived particulate air pollution is associated with a deterioration of asthma in children and adults, chronic obstructive pulmonary disease (COPD) in the elderly [4-6], as well as increases in cardiovascular morbidity and mortality [7-10].

Diesel exhaust (DE) has been shown to be a predominant contributor to urban fine particulate matter contributing to adverse health effects [11]. Previous experimental human exposure studies have demonstrated that exposure to diesel engine exhaust induces a wide range of airway inflammatory responses including increased inflammatory cell infiltration along with an enhanced cytokines release through the activation of redox-sensitive transcription factors [12-14]. We have also previously demonstrated impaired vasomotor function and endogenous fibrinolysis, enhanced ex vivo thrombus formation and increase arterial stiffness in subjects following controlled diesel exhaust challenge [15-17]. Furthermore, we have demonstrated that exhaust particle traps not only reduce the emission particle mass and number but also prevent cardiovascular and prothrombotic effects [18].

Exposure to traffic-derived air pollution is therefore of major public health concern in urban areas, estimated by the WHO to result in 3.2 million deaths annually worldwide [19], and there is an urgent need to consider and evaluate strategies to reduce individual exposures [20]. Whilst the best strategy, with the widest possible benefit to the population, would be to reduce emissions though legislation, as was achieved for coal $[21,22]$ and cigarette smoke $[23,24]$, such interventions for traffic are challenged by economical and political difficulties. Other strategies are therefore required, either through improved tailpipe emissions abatement technologies, or traffic management schemes. In addition, the use of tail-pipe particle filters has been shown to reduce many of the adverse cardiovascular effects of diesel exhaust exposure, and the use of a highly efficient facemask in heavily polluted urban areas is associated with small improvements in blood pressure, heart rate variability, myocardial ischemia and respiratory symptoms $[25,26]$. However, much of an individual's exposure to trafficderived air pollution may actually be received whilst commuting in traffic within vehicles or walking or cycling in urban areas [6]. Recent studies have shown that exposure to PM within a car or bus is often $20-70 \%$ higher than for cyclists along a similar route $[27,28]$. Modern in-car filtration systems can actually reduce PM exposure within cars significantly [29], and similar filtration systems within people's homes have been shown to both reduce exposure to $\mathrm{PM}$ and improve measures of microvascular function [30].
We therefore suggest that the approach to protect individuals from PM exposure is to target in-car exposures by means of highly efficient air inlet filters. This concept was previously investigated by employing cabin air filters in an experimental human diesel exhaust exposure study. It was demonstrated that particle filters with active charcoal significantly reduced symptoms [31]. The study led to the application of scientifically evaluated cabin air inlet filters by the vehicle industry.

The present investigation focuses on the efficacy of modern air inlet filters. We evaluated the efficacy and ability of a series of newly developed cabin air filters to decrease DE-induced respiratory symptoms in healthy volunteers. In addition, we also examined whether the filters altered the oxidative and pro-inflammatory potentials of the residual particles penetrating the filter to the breathing zone of the subjects. We hypothesized that reduction of PM mass, as well as other components of the diesel exhaust aerosol by cabin filters would reduce irritant symptoms and reduce adverse health effects.

The aim of this study was evaluate the efficacy of different vehicle cabin air inlet filters to reduce the diesel exhaust induced symptomatic responses in healthy subjects.

\section{Methods \\ Subjects}

Thirty healthy volunteers (mean age 25, range 18-29, 17 males, 13 females, all never smokers) were recruited. All subjects underwent a physical examination, baseline blood count and renal function assessment, spirometry $\left(\mathrm{FEV}_{1}\right.$, $\mathrm{VC}, \mathrm{FEV}_{1} / \mathrm{VC}$ ) and 12-lead electrocardiogram prior to participation. All subjects completed a cardiopulmonary exercise test on an upright bicycle ergometer to determine the workload required to produce an average minute ventilation of $20 \mathrm{~L} / \mathrm{min} / \mathrm{m}^{2}$ body surface area. All subjects gave their written informed consent and the study was approved by the local ethical review board, and carried out in accordance with the Declaration of Helsinki.

\section{Exposures}

Subjects were exposed separately to filtered air or diesel exhaust, filtered and unfiltered, on four separate occasions in a randomized double-blind controlled crossover manner (see Additional file 1: Figure S1 for graphical presentation). Filtration of the diesel exhaust was done with two separate filters; Filter A, which was a particle filter and Filter B, which was the same particle filter with an active charcoal filter medium added. The exposures were separated by at least one week. Each exposure lasted for one hour during which the subjects performed moderate physical exercise (minute ventilation $20 \mathrm{~L} / \mathrm{min} / \mathrm{m}^{2}$ body surface area) on a bicycle ergometer for $15 \mathrm{~min}$ followed by $15 \mathrm{~min}$ rest, repeated during the second half of the exposures [32]. During 
filtered air exposures, the engine was also running, but no exhaust was fed into the chamber.

\section{Diesel generation and particle characterization}

Diesel exhaust was generated by an idling Volvo diesel engine (Volvo TD40 GJE, 4.0 L, four cylinders, 1996) running on a well-characterized diesel fuel (Preem, UN 1202, VSD 10) as previously described [33] and outlined in detail within the Additional file 2. As shown in Figure 1, the tested filters were located prior to the airflow entering the chamber, in a similar way as in our earlier work [31]. During the occasions with filtered air and unfiltered diesel exhaust exposures the test filters were removed from the cabinets, thus enabling the same air/exhaust flow conditions with and without the studied filters in operation. The tubing immediately before and after the filter, which was located immediately before the air entered the chamber, allowed for continuous control of pressure changes across the filters as well as SMPS measurements. For the two filters employed for the human exposure studies, the particle number size distributions in the chamber determined by a scanning mobility particle sizer (SMPS) ranged from 0.014 to $0.660 \mu \mathrm{m}$ (mobility diameter) with a bimodal distribution with peaks at around 20-40 nm (nucleation mode) and at 100-130 nm (accumulation mode) similar to our previous studies and as shown in Additional file 3: Figure S2 [34]. The SMPS system consisted of a differential mobility analyzer (DMA, TSI model 3071, TSI Inc., United States) and a condensation particle counter (CPC, TSI model 3010, TSI Inc., United States).

\section{Outcome measures}

The primary aim of the current study was to evaluate symptoms following exposure to filtered and un-filtered diesel exhaust in human subjects. The impact of passing the diesel exhaust aerosol through the filters on measures of systemic inflammation and lung function responses in humans in vivo represented secondary analysis. General subjective symptoms of well-being (headache, eye irritation, nasal irritation, unpleasant smell, throat irritation, bad taste, nausea, cough and difficulty in breathing) were assessed by questionnaire before and every 15 minute throughout the duration of the exposure, with scores based on a modified Borg scale, ranging from no symptoms (ranked 0) to maximal symptoms (ranked 11) [35]. Spirometry with determination of $\mathrm{FEV}_{1}$ and $\mathrm{FVC}$ was performed before and one hour after each exposure using a Jaeger MSC Spirometer (Germany). Blood samples were obtained at baseline and 5 hours after exposure. The samples were centrifuged at $3,000 \mathrm{~g}$ for $30 \mathrm{~min}$ at $4^{\circ} \mathrm{C}$ before plasma was removed and frozen at $-80^{\circ} \mathrm{C}$ for further analysis. Plasma samples were analysed for markers of acute inflammation: Interleukin- 6 (IL6), tumor necrosis factor-alpha (TNF $\alpha$ ), P-selectin, soluble Intercellular Adhesion Molecule-1 (sICAM-1), and cluster of differentiation 40 ligand (CD40L) using DuoSet ELISA kits (R\&D Systems, Abingdon, UK), according to

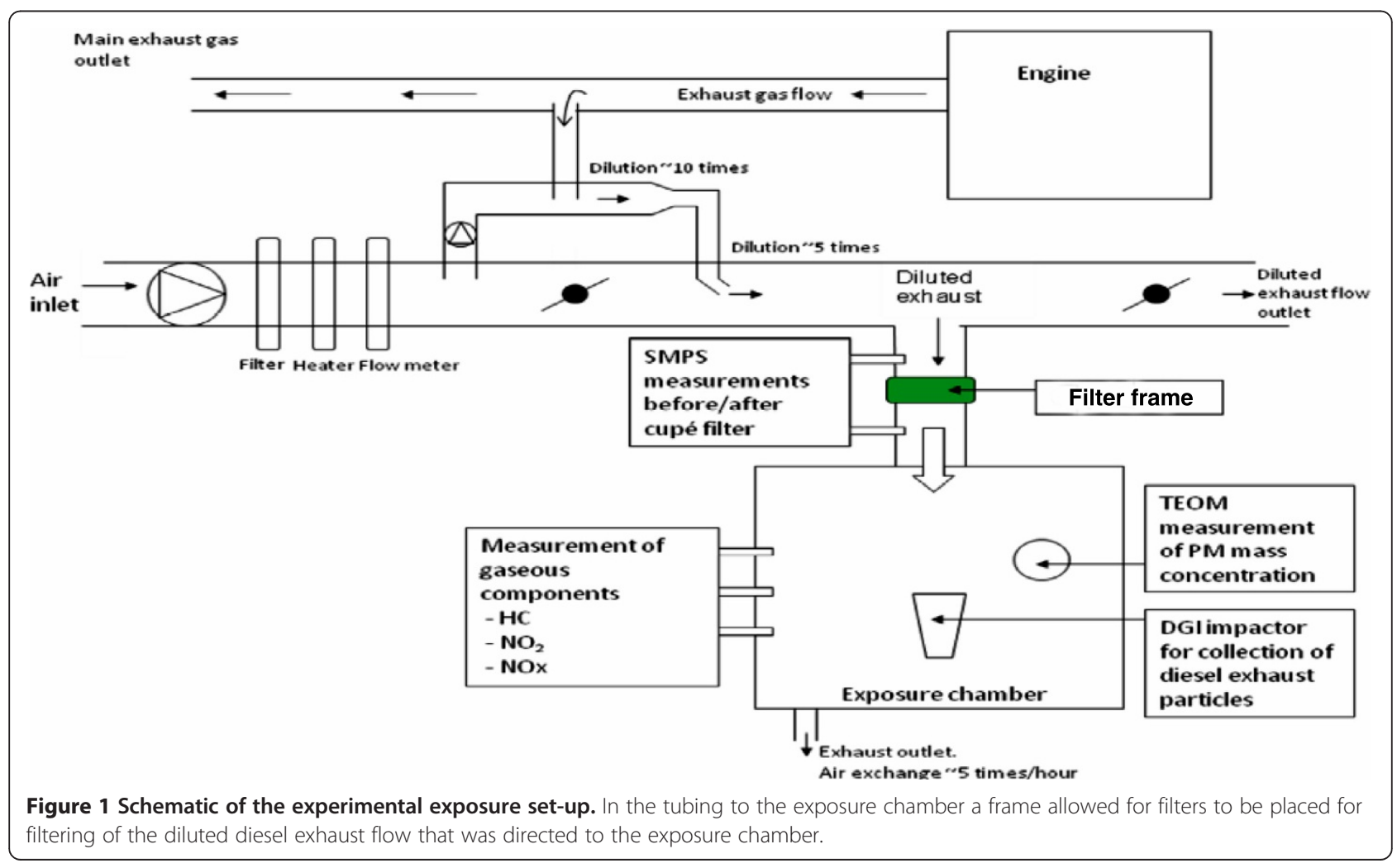


the manufacturer's instructions. IL- 8 was not measured in peripheral blood as previous investigations have shown its usefulness for evaluating lung responses reflected in bronchial biopsies and bronchoalveolar lavage, but not in blood.

\section{In vitro-testing of the PM penetrating into the chamber}

Four filters, including the two selected for the human exposure campaign, were analysed regarding influence on oxidative and inflammatory potential. Details of their filtering capacity, PM sampling, extraction and analysis of oxidative and inflammatory potentials are summarized in the Additional file 2 and Additional file 4. Briefly, PM oxidative potential was assessed in a synthetic respiratory tract lining fluid (RTLF) model at a particle concentration of $50 \mathrm{mg} / \mathrm{ml}$. PM oxidative potential was expressed as the percentage loss of ascorbate and glutathione form this model over a 4 hour incubation $\left(\mathrm{pH} 7.4,37^{\circ} \mathrm{C}\right)$ as previously described [36,37].

The human type II alveolar epithelial cell line A549 (ATCC CCL-185) was cultured in RPMI 1640 medium (Gibco BRL, Paisley, UK) supplemented with 10\% fetal calf serum (FCS, HyClone, Perbio Science, Aalst, Belgium) and $50 \mu \mathrm{g} / \mathrm{mL}$ gentamicin. All cells were maintained at $37^{\circ} \mathrm{C}$ in a humidified atmosphere with $5 \% \mathrm{CO}_{2}$. For experiments, cells were seeded in 24-well culture plates at $5 \times 104$ cells per well and allowed to attach overnight before particle stimulation. Stock solutions of particles were generated at a concentration of $5 \mathrm{mg} / \mathrm{mL}$ in a solution of $0.0004 \%$ dipalmitoyl lecithin (DPL; Sigma) in distilled water and sonicated for $4 \times 1 \mathrm{~min}$, with vortexing in between. Particles were diluted in cell culture medium without FCS or supplements and used at $10,30,50$ or $100 \mu \mathrm{g} / \mathrm{cm}^{2}$. After a 24-hour incubation the cell free supernatants were harvested and the concentrations of IL-8 were measured using DuoSet ELISA kits (R\&D Systems, Abingdon, UK). After removal of supernatants, the cells were washed with PBS and visually given a viability score, assessing cells as either normal, slightly inhibited, growth inhibited or dead.

The decision of which filters that should be included in the human exposure study was based on their filtering efficacy, in-vitro study data and our experiences from the preceding cabin air filter study [32]. While filter D had the highest particle filtration capacity, it lacked an active charcoal component, which previously had been shown to be of importance to significantly reduce symptoms in human subjects exposed to diesel exhaust [31]. Therefore filter B, which was a particle filter with active charcoal and high filtrating capacity, was selected as most promising. Filter A, which was the same filter but without charcoal, was included as reference.

\section{Statistics}

Normality was tested using the Shapiro-Wilk test. Symptom score and inflammatory markers were expressed as medians with inter-quartile range, with lung function and air pollutant data presented as means \pm standard deviation. The Wilcoxon Signed-Rank test was used for calculations of differences between the delta changes (maximal minus pre-exposure symptom score) across the exposures. McNemar's Chi-square test was performed to analyze the difference between the number of subjects reporting symptoms after exposure to unfiltered and filtered DE. The Wilcoxon Signed-Rank test was used to compare the delta change in inflammatory markers in the peripheral blood (change in concentration at 5 hours after exposure minus before exposure) across the exposures. The delta changes in lung function across exposures (one hour after exposure minus before exposure) were compared using pairedsample Student's $t$ Test. The primary comparisons were done between filtered and unfiltered DE. A secondary comparison was done between the two filters examined.

Oxidative capacity of unfiltered and filtered diesel exhaust particles was analysed using the Kruskal-Wallis One-way-analysis of variance (ANOVA) with post hoc analysis with the Games-Howell test for groups of unequal size and variances. Pro-inflammatory effects of unfiltered and filtered diesel exhaust particles were analysed using One-way analysis of variance (ANOVA) with Dunnett's Multiple Comparison Test. To compare the efficacy of filter A-D with unfiltered DEP, a two-way ANOVA with Tukey's multiple comparison test was performed. P values of $<0.05$ were considered significant.

Data were analysed using SPSS (SPSS Inc. Chicago, IL, USA, version 17) and GraphPad Prism (GraphPad Software, version 5 for PC).

\section{Results}

\section{Exposure details}

During the unfiltered DE exposure the mean PM concentrations within the chamber was $350 \mu \mathrm{g} / \mathrm{m}^{3}$, with $\mathrm{NO}$ and $\mathrm{NO}_{2}$ concentrations of 2.49 and $0.68 \mathrm{ppm}$, respectively (Table 1). Filter A was found to reduce the average $\mathrm{PM}_{1}$ mass concentration by $47 \%(\mathrm{P}<0.001)$ and the particle number concentration by $36 \%(P=0.01)$. Filter $B$, which contained an active charcoal component, was even more effective, reducing $\mathrm{PM}_{1}$ mass by $74 \%(\mathrm{P}<0.001)$, with an associated reduction in particle number by $75 \%(\mathrm{P}=0.001)$ (Table 1). The combination filter also reduced the concentrations of $\mathrm{NO}_{2}$ by $85 \%(\mathrm{P}<0.001)$, whilst Filter A showed no significant effect on $\mathrm{NO}_{2}$. Hydrocarbon concentrations were not significantly reduced with filter A, but filter $\mathrm{B}$ reduced concentrations by an average of $58 \%(\mathrm{P}<0.001)$.

\section{Symptomatic responses}

All of the subjective symptoms examined, eye and nasal irritation, bad smell and taste, plus headache, were experienced in an increased proportion of the subjects following the unfiltered DE challenge compared with filtered air. 
Table 1 Pollutant concentrations in the exposure chamber during exposure to filtered air, as well as filtered and unfiltered diesel exhaust challenges

\begin{tabular}{ccccc}
\hline Exhaust component & Filtered air $(\mathbf{n}=\mathbf{3 0})$ & Unfiltered DE (28) & Diesel exhaust filter $\mathbf{A}(\mathbf{n}=\mathbf{2 9})$ & Diesel exhaust filter B $(\mathbf{n}=\mathbf{2 8})$ \\
\hline $\mathrm{PM}_{1}\left(\mu \mathrm{g} / \mathrm{m}^{3}\right)$ & $4.6 \pm 1.7$ & $350 \pm 72$ & $183 \pm 18^{* * *}$ & $93 \pm 16^{* * *}$ \\
Particle number $\times 10^{5} / \mathrm{cm}^{3}$ & $\mathrm{n} / \mathrm{a}$ & $54 \pm 10$ & $30 \pm 6^{*}$ & $15 \pm 3^{* *}$ \\
$\mathrm{NO}(\mathrm{ppm})$ & $0.00 \pm 0.00$ & $2.49 \pm 1.01$ & $2.21 \pm 0.66$ & $1.77 \pm 0.55^{* *}$ \\
$\mathrm{NO}_{2}(\mathrm{ppm})$ & $0.00 \pm 0.00$ & $0.68 \pm 0.29$ & $0.58 \pm 0.20$ & $0.10 \pm 0.04^{* * *}$ \\
Hydrocarbons $(\mathrm{ppm})$ & $0.00 \pm 0.00$ & $2.41 \pm 0.81$ & $1.85 \pm 0.60^{*}$ & $1.02 \pm 0.11^{* * *}$ \\
\hline
\end{tabular}

Data are given as mean \pm SD. T-tests were performed to analyze differences in pollutant concentrations between unfiltered DE and DE exhaust after the use of the cabin filters. $P$ values of $<0.05$ were considered significant: ${ }^{*} P<0.05$, ${ }^{* *} P<0.01,{ }^{* * *} P<0.001$.

Figure 2 displays the number of subjects reporting symptoms after each exposure. Filter B significantly reduced the number of subjects reporting eye irritation, nasal irritation and bad taste compared with unfiltered DE $(\mathrm{p}<0.05-0.01)$

A more detailed description of the influence of symptoms by the different exposures, on an individual subject level, is given in Figures 3,4 and 5. Eye irritation (Figure 3), nasal irritation (Figure 4) and unpleasant smell (Figure 5) were confirmed to be significantly reduced after exposure with diesel exhaust filtered with filter B (combined particle and active charcoal filter) compared with unfiltered exhaust $(\mathrm{p}=0.002-<0.001$, Wilcoxon). Only a few subjects experienced eye irritation before and after the filtered air exposure, the proportion increasing to 18 out of 28 following the unfiltered diesel exhaust challenge. Filter B was associated with a significant $(\mathrm{P}<0.001) 80 \%$ reduction in eye

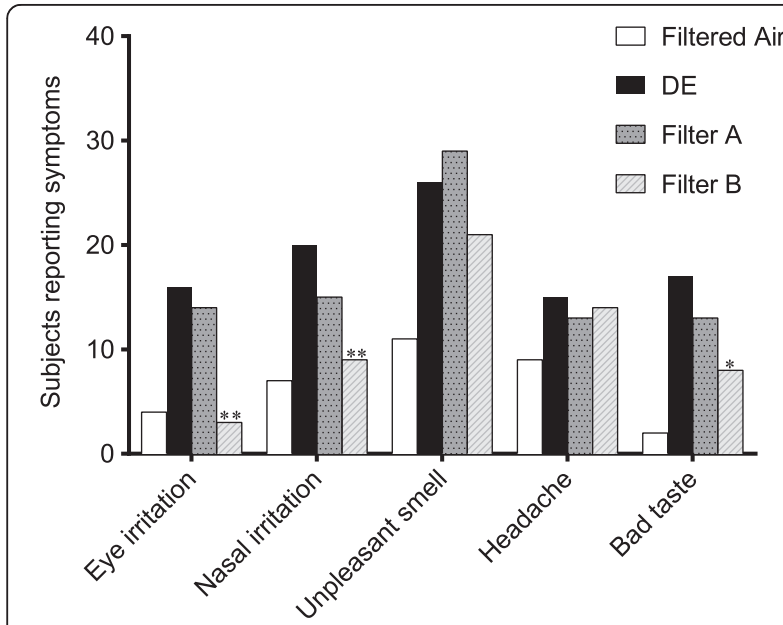

Figure 2 Number of subjects reporting symptoms after exposure to filtered air, unfiltered diesel exhaust (DE), diesel exhaust with filter A (ultrafine particle filter) and with filter B (ultrafine particle filter with active charcoal). McNemar's Chi-square test was performed to analyze the difference between the number of subjects reporting symptoms after exposure to unfiltered DE and diesel exposure filtered with filters A and B. Data were considered significant at ${ }^{*} \mathrm{P}<0.05,{ }^{* *} \mathrm{P}<0.01$ irritation. A similar pattern was seen with nasal irritation, with unfiltered diesel exhaust eliciting symptoms in 20 out of 28 subjects reducing significantly $(\mathrm{P}<0.001)$ to only $6 / 28$ after inclusion of filter $B$ in the exhaust outlet. Filter A did not appear to significantly affect the individual symptom perception. A secondary analysis was performed examining the efficacy to reduce symptoms between Filters A and B. Filter B was significantly more effective in reducing eye irritation, nasal irritation and unpleasant spell and bad taste than filter $\mathrm{A}(\mathrm{p}<0.01$, $\mathrm{p}<0.01, \mathrm{p}<0.01$ and $\mathrm{p}<0.02$, respectively.

\section{Respiratory function test}

Exposure to unfiltered diesel exhaust was not associated with a significant reduction in any of the Spirometric variables examined (Table 2). When the delta responses in $\mathrm{FEV}_{1}$ (post minus pre-values), of each of the unfiltered and filtered diesel challenges were examined, there was evidence of a statistical reduction $(P=0.035)$ in the $\mathrm{FEV}_{1}$ response with $\mathrm{DE}$, plus filter $\mathrm{B}$, versus unfiltered DE, but the difference was small, of no clinical significance and difficult to interpret in the absence of a DEinduced decrement in the forced expiratory variables.

\section{Systemic markers of inflammation}

No changes in the concentration of any of the markers of systemic inflammation were observed when responses across the filtered air and unfiltered DE exposure were compared (Table 3). Again when the responses across each of the DE exposures were compared there was evidence of a significant reduction in the sICAM-1 responses with both DE passed through filter A $(\mathrm{P}=0.040)$ and $B(P=0.026)$ compared with the unfiltered $D E$ exposure, but again the response was minimal and difficult to explain in the absence of a clear systemic response with the unfiltered DE.

\section{In vitro measurements}

We also examined the oxidative and inflammatory potential of both the unfiltered DE PM and the PM penetrating the filters to reach the subjects in the chamber. These data are provided in the online supplement 

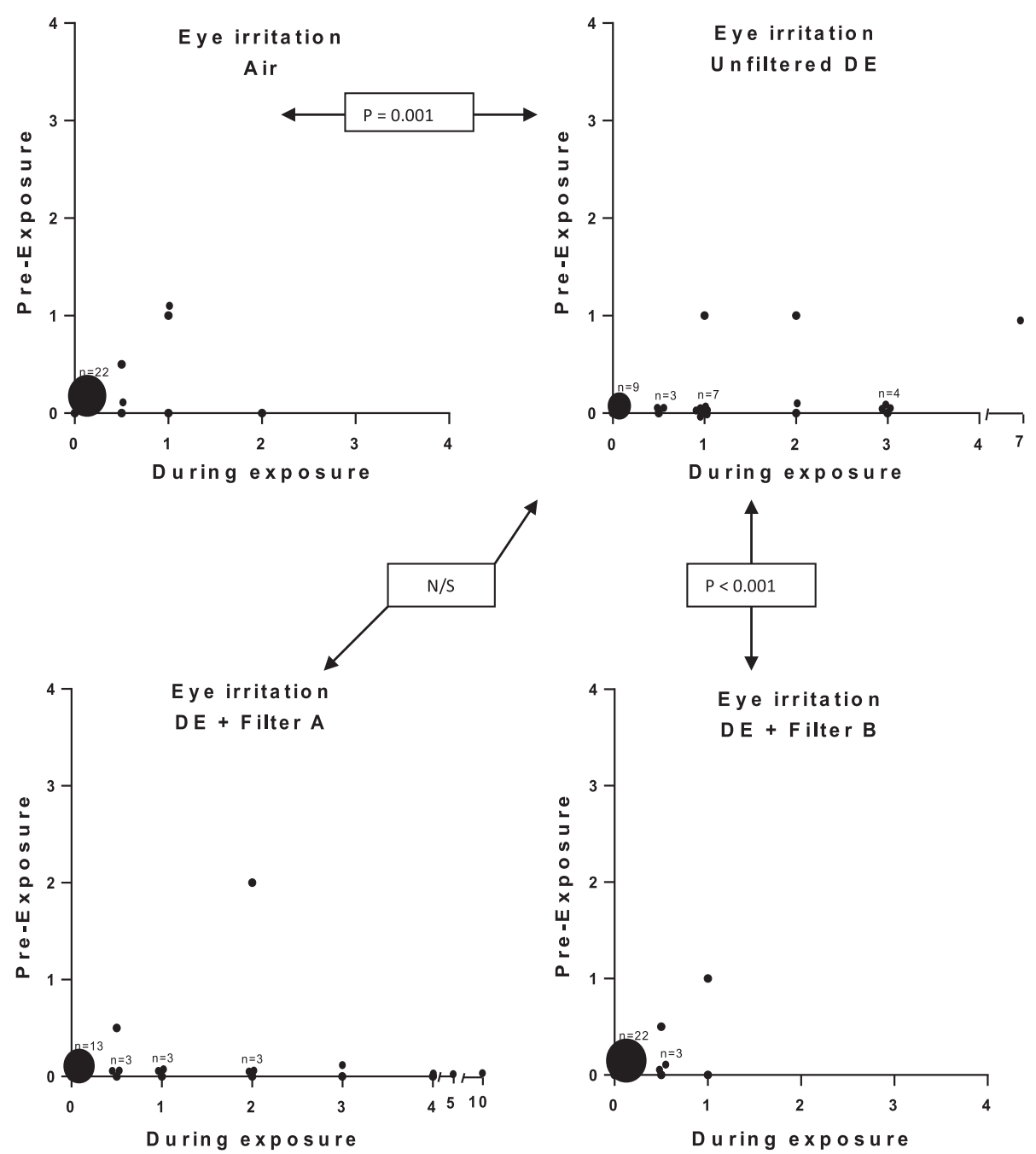

Figure 3 Graphical illustration of the perception of eye irritation during exposure to filtered air, unfiltered diesel exhaust, and diesel exhaust filtered with Filter A and B, respectively. The symptom score is presented both pre- and post-exposure according to a modified Borg scale. A shift toward the right indicates increased symptoms during exposure. Each individual is represented by one data point. Where data from several subjects are clustered, the number ( $\mathrm{n}$ ) of subjects is indicated. Wilcoxon's Signed-Rank test was used for comparison of absolute delta values (Max symptom score minus before exposure) across exposure to unfiltered DE and filter air, unfiltered DE and DE filtered with filter $A$ and unfiltered DE with DE filtered with filter B (active charcoal containing filter). Data were considered significant at $p<0.05$. Significant differences between air and unfiltered diesel exhaust, and diesel exhaust filtered with filter A (particle filter) and B (particle and active charcoal filter) are given in the figure. DE with filter B gave significantly less symptom than filter A.

(Additional file 5: Figure S4 and Additional file 6: Figure S5). The oxidative potential, assessed by the capacity of the sampled PM to drive the oxidation of ascorbate and glutathione from a simple synthetic respiratory tract lining fluid, was low for all PM samples and was not affected by passing the PM through either of the filters tested when examined on a per unit mass (per $\mu \mathrm{g}$ ) basis (Additional file 5: Figure S4). The DE particles collected after passing through Filter A, C and D significantly increased IL-8 production from A549 cells. In contrast DE particles filtered by Filter B, which included activated charcoal, did not cause any significant increase in IL-8 release vs. diluent control and the IL-8 levels at the 30 ,
50 and $100 \mu \mathrm{g} / \mathrm{cm}^{2}$ concentrations were significantly lower than for Unfiltered DE $(\mathrm{P}<0.05-0.0001)$. Cell viability was scored visually and up the concentration 30 $\mathrm{ug} / \mathrm{cm}^{2}$ the cells were unaffected by all particle samples. At higher particle concentrations unfiltered DE and particles from filter A had the highest effects on cell viability. Filter B with active charcoal showed less cytotoxic effects (Additional file 6: Figure S5).

\section{Discussion}

In this study we demonstrated that the use of an air cabin inlet filter, especially when combined with an active charcoal component, effectively reduces exposure to 

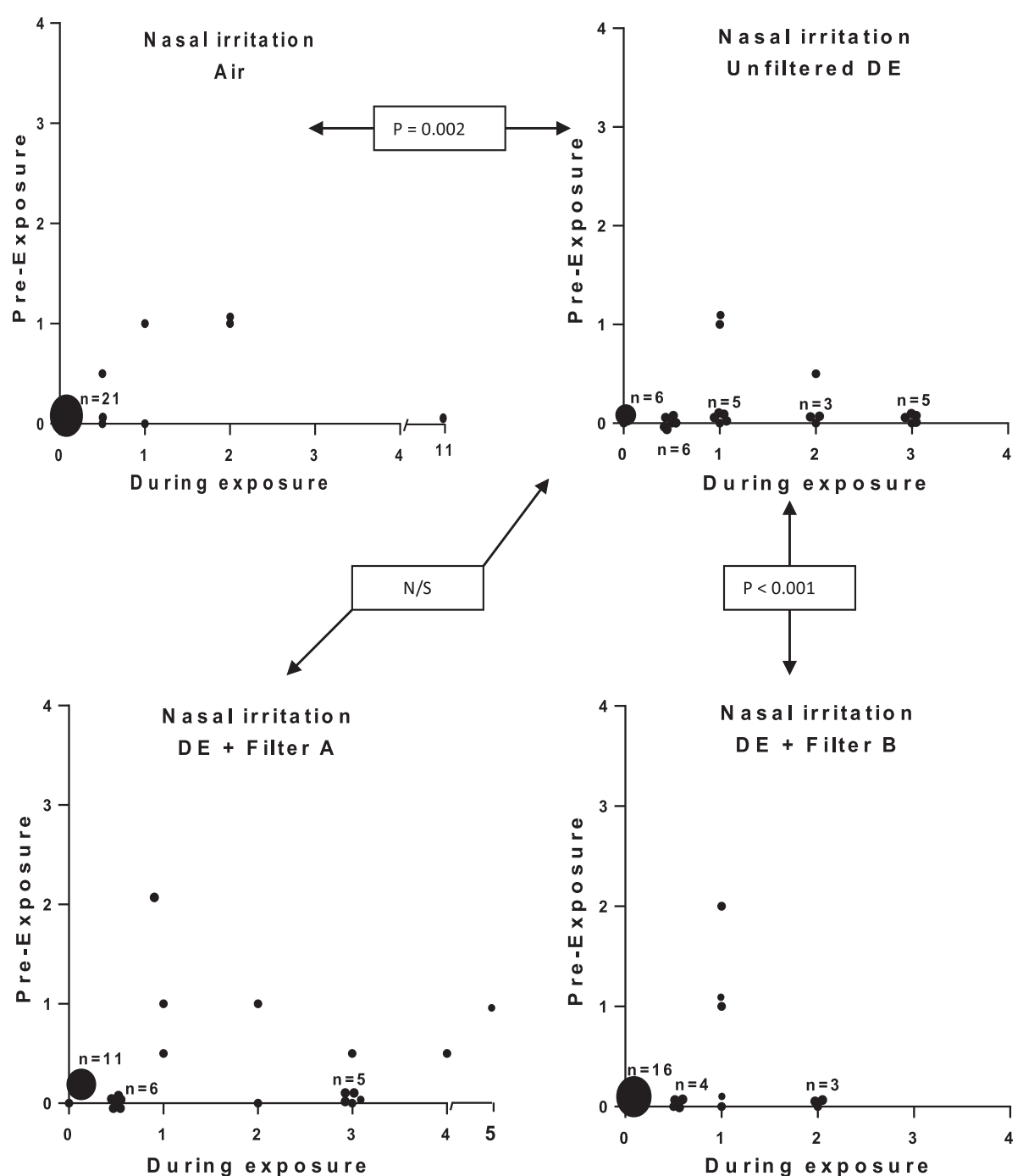

Figure 4 Graphical illustration of nasal irritation during exposure to filtered air, unfiltered diesel exhaust, and diesel exhaust filtered with Filter A and B, respectively. Details of the figure and statistical analysis are as outlined in the legend to Figure 3.

$\mathrm{PM}, \mathrm{NO}_{\mathrm{x}}$ and hydrocarbons from freshly-generated diesel engine exhaust, improves symptoms and reduces the adverse effect of DE in healthy volunteers, along with decrease in the oxidative and pro-inflammatory effects of the particles which do penetrate the filter. The widespread adoption of such effective air cabin filters has the potential to significantly improve cardiovascular and respiratory health.

\section{Evaluation of cabin air filters by diesel exhaust exposures} in human subjects

Filters A and B were selected for the human exposure study. These filters share the same effective filtering medium, but filter B additionally contains an active charcoal component. The addition of active charcoal to a filter has previously been shown to be beneficial to reduce symptoms following exposure to diesel exhaust [31].
Exposure to traffic-derived air pollution in general and diesel exhaust in particular, has been widely associated with adverse respiratory as well as cardiovascular health effects $[6,8]$. As a consequence, there is a need to explore different strategies to protect exposed individuals, as expressed by Brook et al in an American Heart Association statement [20]. In this study we have evaluated one possible strategy to reduce PM exposure for commuters and car occupants, given the evidence that this PM exposure in day-to-day life is significantly related to adverse health effects [38].

We demonstrated that the use of an air cabin inlet filter, especially when combined with an active charcoal component, was highly effective to reduce exposure to $\mathrm{PM}, \mathrm{NO}_{\mathrm{x}}$ and hydrocarbons from engine exhaust; with evidence that the combination filter also modified the toxicity of the filtered particles making 

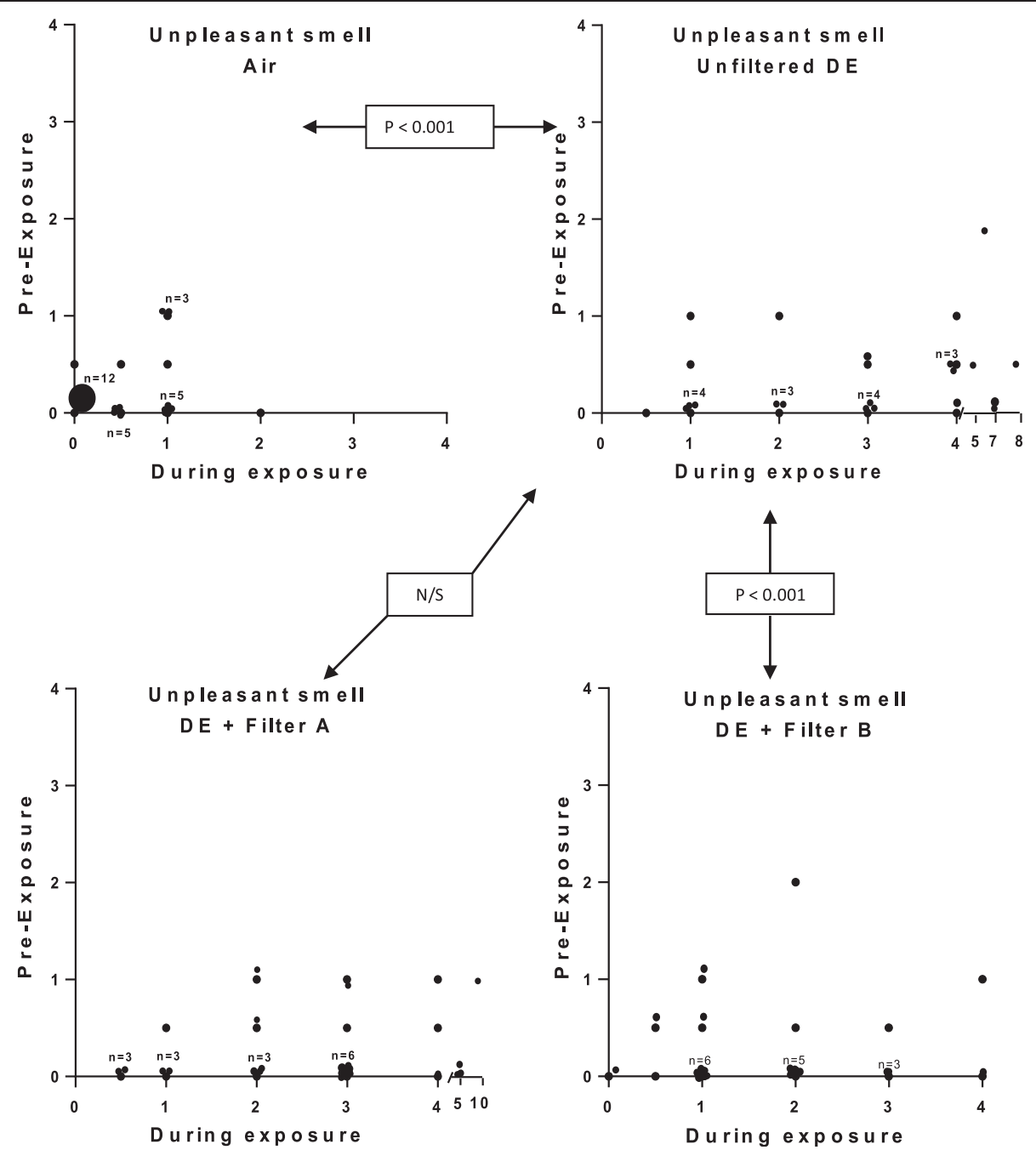

Figure 5 Graphical illustration of unpleasant smell during exposure to filtered air, unfiltered diesel exhaust, and diesel exhaust filtered with Filter A and B, respectively. Details of the figure and statistical analysis are as outlined in the legend to Figure 3.

them less pro-inflammatory in-vitro after filtration. When considering the ability of filters for vehicle cabins to reduce health effects, there are two main properties that are of consideration; 1) the ability to filter particles which is dependent on the mesh and structure of the filter and 2) the ability to filter gaseous components, which depends on adsorption. A partial reduction of particles only may not necessarily be sufficient on its own. We previously addressed this in a bronchoscopy study in human subjects, in which an exhaust pipe filter reduced the particle mass in the exposure chamber roughly by half, but this was insufficient to diminish the diesel exhaust-induced airway inflammatory responses [39]. Similarly, a partial reduction of diesel exhaust particles by an air inlet filter in a preceding study [31] failed to significantly reduce symptoms, whereas the addition of an active charcoal filter component improved the filtering and significantly reduced symptoms. Active charcoal has in the present as well as previous investigations been confirmed to adsorb gaseous components such as $\mathrm{NO}_{2}$ and hydrocarbons [31]. There is an extensive literature, which suggests that the pro-inflammatory properties of particles are dependent on the particles' physical characteristics in combination with their chemical properties [40,41]. Hydrocarbons in diesel exhaust, such as aliphates and PAHs, induce substantial pro-inflammatory effects and mitochondrial dysfunction and we have previously documented these chemical entities to be adsorbed by active charcoal filters [31]. In the present study, the combination filter $\mathrm{B}$ including active charcoal, reduced hydrocarbons by half compared with no effect by a particle filter only, and was also superior in reducing both particle number and mass by as much as $75 \%$. The improved particle filtering capacity is expected to be due to the 
Table 2 Spirometry data before and 1 hour after exposure to filtered air, unfiltered diesel exhaust (DE) and diesel exhaust filtered by filter $A$ and $B$

\begin{tabular}{|c|c|c|c|c|c|c|c|c|c|c|c|c|}
\hline & \multicolumn{3}{|c|}{$\begin{array}{l}\text { Filtered air } \\
\qquad(n=30)\end{array}$} & \multicolumn{3}{|c|}{$\begin{array}{l}\text { Unfiltered DE } \\
\quad(n=28)\end{array}$} & \multicolumn{3}{|c|}{$\begin{array}{c}D E+\text { filter } A \\
(n=29)\end{array}$} & \multicolumn{3}{|c|}{$\begin{array}{c}D E+\text { filter B } \\
(n=28)\end{array}$} \\
\hline & Before & $1 \mathrm{~h}$ after & Delta & Before & $1 \mathrm{~h}$ after & Delta & Before & $1 \mathrm{~h}$ after & Delta & Before & $1 \mathrm{~h}$ after & Delta \\
\hline $\mathrm{FEV}_{1}$ & $4.27 \pm 0.66$ & $4.23 \pm 0.63$ & $-0.43 \pm 0.19$ & $4.30 \pm 0.60$ & $4.23 \pm 0.58$ & $-0.04 \pm 0.1$ & $4.30 \pm 0.64$ & $4.27 \pm 0.62$ & $-0.02 \pm 0.09$ & $4.24 \pm 0.64$ & $4.25 \pm 0.64$ & $0.01 \pm 0.95^{*}$ \\
\hline FVC & $5.56 \pm 1.01$ & $5.48 \pm 0.99$ & $-0.07 \pm 0.19$ & $5.60 \pm 0.91$ & $5.49 \pm 0.94$ & $-0.6 \pm 0.16$ & $5.62 \pm 0.90$ & $5.60 \pm 0.93$ & $-0.2 \pm 0.26$ & $5.59 \pm 0.97$ & $5.52 \pm 0.97$ & $-0.05 \pm 0.17$ \\
\hline $\mathrm{FEV}_{1} / \mathrm{FVC}$ & $77.45 \pm 6.29$ & $77.0 \pm 6.80$ & $0.24 \pm 2.9$ & $77.29 \pm 6.33$ & $78.23 \pm 7.39$ & $0.72 \pm 2.91$ & $76.84 \pm 6.70$ & $76.84 \pm 6.71$ & $-0.00 \pm 3.54$ & $75.74 \pm 6.08$ & $77.57 \pm 6.10$ & $1.8 \pm 3.82$ \\
\hline
\end{tabular}

Data are given as mean \pm SD. Paired sample T-test was used to compare means of delta changes (1 hour post minus pre exposure) between exposure to unfiltered DE and filter air, unfiltered DE and DE filtered with filter $A$, and unfiltered DE with DE filtered with filter $B$ (active charcoal containing filter). A $p$-value of $<0.05$ was considered significant. ${ }^{*} \mathrm{P}<0.05$. 
Table 3 Inflammatory markers before and $\mathbf{5}$ hours after exposure to filtered air, unfiltered diesel exhaust (DE) and diesel exhaust filtered by filter A and B

\begin{tabular}{|c|c|c|c|c|c|c|c|c|c|c|c|c|}
\hline & \multicolumn{3}{|c|}{$\begin{array}{l}\text { Filtered air } \\
\qquad(\mathrm{n}=28)\end{array}$} & \multicolumn{3}{|c|}{$\begin{array}{l}\text { Unfiltered DE } \\
\qquad(n=28)\end{array}$} & \multicolumn{3}{|c|}{$\begin{array}{l}\text { Diesel exhaust }+ \text { filter A } \\
\qquad(n=28)\end{array}$} & \multicolumn{3}{|c|}{$\begin{array}{l}\text { Diesel exhaust + filter B } \\
\qquad(n=28)\end{array}$} \\
\hline & Before & 5 hours after & Delta & Before & 5 hours after & Delta & Before & 5 hours after & Delta & Before & 5 hours after & Delta \\
\hline IL-6 & 0.60 & 0.68 & -0.06 & 0.64 & 0.77 & 0.1 & 0.69 & 0.73 & -0.03 & 0.65 & 0.69 & 0.04 \\
\hline $\mathrm{pg} / \mathrm{ml}$ & $0.38-0.96$ & $0.43-1.01$ & $-0.16-0.15$ & $0.34-1.01$ & $0.49-1.02$ & $-0.09-0.3$ & $0.64-0-97$ & $0.54-1.04$ & $-0.15-0.22$ & $0.39-0.86$ & $0.4-1.22$ & $-0.19-0.26$ \\
\hline TNF-a & 0.69 & 0.55 & -0.08 & 0.72 & 0.61 & -0.02 & 0.88 & 0.91 & -0.05 & 0.72 & 0.65 & -0.11 \\
\hline $\mathrm{pg} / \mathrm{ml}$ & $0.48-0.93$ & $0.25-0.86$ & $-0.25-0.02$ & $0.42-1.05$ & $0.24-1.00$ & $-0.25-0.05$ & $0.55-1.24$ & $0.39-1.09$ & $-0.25-0.07$ & $0.45-0.97$ & $0.28-1.16$ & $-0.19-0.08$ \\
\hline p-selectin & 69.8 & 64.7 & -0.11 & 60.0 & 62.6 & 1.23 & 64.4 & 69.0 & -1.98 & 66.6 & 66.6 & 2.52 \\
\hline $\mathrm{ng} / \mathrm{ml}$ & $54.4-80.1$ & $56.7-74.2$ & $-12.7-10.15$ & $45.9-76.1$ & $49.9-77.2$ & $-3.88-10.0$ & $55.9-86.7$ & $54.8-74.1$ & $-17.1-10.8$ & $53.1-83.5$ & $54.9-87.45$ & $-17-4-8.6$ \\
\hline s-ICAM-1 & 251 & 260 & 3.72 & 245 & 244 & 9.29 & 265 & 257 & -0.93 & 298 & 297 & -0.83 \\
\hline $\mathrm{ng} / \mathrm{ml}$ & 208-299 & $223-312$ & $-16.7-58.5$ & $193-278$ & $214-297$ & $-19.1-42.76$ & $220-329$ & $211-327$ & $-42.4-18.9^{*}$ & $244-318$ & $227-318$ & $-30.1-22.8^{*}$ \\
\hline CD40L & 246 & 268 & 29.86 & 270 & 244 & -13.23 & 332 & 249 & -11.36 & 316 & 251 & -78.98 \\
\hline $\mathrm{pg} / \mathrm{ml}$ & $181-331$ & $191-367$ & $-70.8-96.1$ & 173-379 & $182-320$ & $-99.4-42.3$ & 215-389 & $159-346$ & $-122.7-48.1$ & $179-434$ & $135-359$ & $-167.3-20.7$ \\
\hline
\end{tabular}

Data were expressed as medians with inter-quartile range. Wilcoxon's Signed-Rank test was used for evaluation of differences between delta changes ( 5 hours post minus pre exposure) across exposure to unfiltered $\mathrm{DE}$ and filter air, unfiltered $\mathrm{DE}$ and $\mathrm{DE}$ filtered with filter $\mathrm{A}$ and unfiltered $\mathrm{DE}$ with $\mathrm{DE}$ filtered with filter $\mathrm{B}$ (active charcoal containing filter). $\mathrm{P}$ values of $<0.05$ were considered significant. ${ }^{*} \mathrm{P}<0.05$. 
higher adsorption capacity by a filter that includes extensive carbon surfaces, which interacts with particles with hydrocarbons on their surface.

We also found support for the interaction between diesel exhaust particles and the active charcoal to be of importance. In the in-vitro experiments, we studied the release of IL-8 from lung epithelial cells exposed to diesel particles. In human experimental studies, employing bronchoscopy with bronchoalveolar lavage and bronchial mucosal biopsies, we have demonstrated a key proinflammatory role for this chemokine in eliciting a neutrophilic airway inflammation through the activation of EGFR, MAPkinase and NFkB pathways [12-14,42-44]. In order to study the toxicological characteristics of the diesel exhaust particles filtered with the various filter media, we chose to expose the cell cultures on an equal particle mass basis. This means that the epithelial cells were cultured with similar particle concentrations, irrespective of the filters actual particle-filtering efficacy. Notably, the combination filter with active charcoal was the only filter to clearly reduce the pro-inflammatory IL8 release from the cells into the culture medium. It should be noted however that within the exposure context, whilst the inflammatory potential was reduced per unit mass compared with the unfiltered condition, the total inflammatory potential reflects the multiple of the activity, plus the actual exposure concentration and therefore this effect was unlikely to influence the in vivo response.

Pro-inflammatory effects were investigated in-vivo in venous blood samples, as a reasonably accessible means to study systemic inflammation in a large scale multiple exposure study, even if it is acknowledged that bronchoscopy sampling, or invasive measures of cardiovascular function, would have given a substantially more detailed view of the effects of DE and the possibility to intervene with filters. The filters in the human in-vivo study were found to cause a modest though statistically significant reduction in S-ICAM1. This could potentially indicate a protective effect on the vasculature and cell migration from the blood stream by the filtering, however, the absence of any significant effect by unfiltered DE vs. filtered air suggests some caution over the interpretation of the finding.

Oxidative stress has been indicated to be an important mechanism contributing to adverse health effects by air pollutants, such as ozone and particles from different sources. In earlier research we have shown diesel exhaust exposure in human subjects to cause oxidative stress, as reflected in bronchoaolveolar lavage fluid $[14,32,45]$. We screened the unfiltered and filtered diesel exhaust particles for oxidative potential, which mimics the interaction of particles with respiratory tract lining fluid (RTLF) but were unable to demonstrate any enhanced or reduced oxidation by either the unfiltered or filtered particles, suggesting that the fresh diesel exhaust has low intrinsic oxidative potential. This contrasts with the high oxidative potential measured at roadside sites with high diesel traffic [46] suggesting that other traffic related sources or processes, such abrasion or aerosol ageing may be important.

In accordance with our previous studies [31], exposure to unfiltered DE increased symptoms such as headache, eye irritation, nasal irritation, unpleasant smell, throat irritation and bad taste. Most of these symptoms were significantly reduced by applying filter $\mathrm{B}$, which included active charcoal. This filter was furthermore significantly better than filter $\mathrm{A}$, which contained the same filter medium but was lacking the efficient charcoal component. The mild headache observed in some subjects was less influenced by this filter compared to most other symptoms, suggesting that there could be room for even further improvements of filter technology. The positive effects of using filter technology for reducing DE-related symptoms and the considerable additional effect of adding an active charcoal component is generally in line with our preceding vehicle air cabin study [31]. It should be noted that the diesel exhaust exposure levels in these studies where symptoms were significantly reduced by filtering, have been confirmed to cause respiratory inflammatory effects as well as cardiovascular adverse effects, reflected as vasomotor dysfunction, impaired endogenous fibrinolysis and ST-T segment changes in healthy and subjects with stable coronary heart disease $[12,15,47,48]$. Reducing symptoms may therefore be accompanied by maintained cardiorespiratory health, which may be of value while driving or travelling in a vehicle, especially in dense and stagnant traffic in metropolitan areas.

\section{Limitations in the study}

In a short-term experimental study, it is only possible to evaluate acute effects, while in real life situations, longterm exposure to traffic-derived air pollution results in increases in cardiovascular and respiratory morbidity and mortality. We have previously demonstrated invasive cardiovascular measurements as well as bronchoscopy evaluation of oxidative and pro-inflammatory effects in the lungs to be powerful tools to study outcomes related to acute adverse effects of traffic exposure $[17,47,48]$. Studies with such techniques are extremely resource demanding and are very difficult to perform with multiple exposures and interventions, but are powerful as has been shown in some studies [18,31]. The decisions were therefore taken to study the interventive effects of the filters in-vitro with a subsequent human experimental study with non-invasive measurements. The sample size was calculated based on a 
preceding study [31] but the study population could in an ideal world have been vastly larger, which could have compensated for some unexpected variability in the degree of the responses. Extending the observation and sampling time to 24-72 hours could potentially have given additional information, especially as regards systemic inflammation. However, the complexity of the study would have been vastly increased. The same applies for lung function measurements, where standard spirometry was mainly included as a safety measure, whereas repeated measurements of airway resistance in a body box during and after exposures have previously been shown to be more sensitive to detect airway constriction.

\section{Conclusions}

The present study has confirmed that cabin air inlet filters have the capacity to substantially reduce exhaustderived particles penetrating into the vehicle cabin. When an efficient filter is combined with an active charcoal component the filtering capacity is enhanced and gaseous components like nitric oxides and hydrocarbons, which have been linked with health effects, are substantially reduced. The combination filter substantially reduced symptoms in human subjects exposed to diesel exhaust and may therefore reduce the adverse health effects for both drivers and passengers. Whilst this solution might be optimal for vehicle users, it is essential that improvements in cabin filters, go hand-inhand with reductions in tailpipe emissions and other regulations to limit the exposure of the population to traffic emissions.

\section{Additional files}

Additional file 1: Figure S1. Flowchart of the human exposure study. Additional file 2: Online supplement.

Additional file 3: Figure S2. Particle number concentrations measured by the SMPS in unfiltered diesel exhaust (DE) immediately prior to the exposure chamber, and after filter $A$ and $B$, respectively. The distributions are given as average distributions with standard deviations.

Additional file 4: Figure S3. Prestudy test data on filtering efficacy in relationship to PM size. Courtesy of Renault. Iso A2 (coarse \& fine particles) \& $\mathrm{NaCl}$ (ultra fine particles) based tests.

Additional file 5: Figure S4. Ascorbate concentrations remaining in a synthetic RTLF following a $4 \mathrm{~h}$ incubation with $50 \mathrm{~g} / \mathrm{ml}$ diesel exhaust particles generated from a diesel engine operating under idling conditions, with and without post exhaust filtering with a variety of cabin filters (A-D). Data are illustrated as means (SD) of between 1-7 separate filters for each condition, with each filter analyzed in triplicate. $\mathrm{CO}=$ the time zero ascorbate concentration; $\mathrm{C} 4$ = the concentration of ascorbate after the $4 \mathrm{~h}$ incubation in the particle free control; $C B=$ the negative control carbon black particle.

Additional file 6: Figure S5. Release of IL-8 from alveolar A549 cells following in-vitro instillation with diesel exhaust particles (DEP) generated from a diesel engine without filtering or with filters A-D. Filter B was a combination filter, which included active charcoal. Cells were incubated with medium alone or with $10,30,50$ or $100 \mu \mathrm{g} / \mathrm{cm} 2$ of particles $(n=4)$. The level of IL-8 in $24 \mathrm{~h}$ supernatants was assessed by ELISA, and expressed as pg/104 cells \pm SD vs. untreated cells. One-way ANOVA with Dunnett's post hoc test was performed to compare with untreated cells. Data were considered significant at ${ }^{*} P<0.05$, ${ }^{* *} P<0.01$, ${ }^{* * *} P<0.001$. Two-way ANOVA with Tukey's post hoc test was used to compare IL8 release data between unfiltered DEP and Filters A-D. Data were considered significant at $+P<0.05,++P<0.01$, $++T P<0.001$, $++t+P<$ 0001. Cell viability is given in the upper right panel as unaffected (OK) growth inhibited or dead.

\section{Competing interests}

This study was commissioned by Renault and funded by means of an unrestricted research grant. Renault had no involvement in the analysis of data or interpretation of the results presented in this paper. S. Couderc and A. Bion are employed by Renault Technocentre, Guyancourt, France.

\section{Authors' contributions}

AM took part in study design, was responsible for coordinating the study, performed the data and statistical analysis and drafted manuscript. SC and $\mathrm{ABI}$ participated in study design and were responsible for filter characterization. $\mathrm{ABU}, \mathrm{MS}$ and $\mathrm{CO}$ carried out in vitro inflammatory cell studies. ISM was responsible for the in vitro oxidative characterization of the particles. CB was involved in particle characterization. JP was responsible for determination of inflammatory markers in in vivo studies. JAB, AFB, JPL, ABL, ISM and TS participated in study design, interpretation of data and drafting of manuscript. All authors read and approved the final manuscript.

\section{Acknowledgements}

The authors acknowledge the advice and analyses by statistician Leif Nilsson. We would like to thank Annika Johansson and Frida Holmström, Jamshid Pourazar, Ann-Britt Lundström, Hans Arvidsson and Maj-Cari Ledin for their invaluable assistance with the human exposure studies.

\section{Author details}

'Department of Public Health and Clinical Medicine, Division of Medicine, Umeå University, Umeå, Sweden. ${ }^{2}$ Renault Technocentre, Guyancourt, France. ${ }^{3}$ Swedish Defence Research Agency, FOl, Umeå, Sweden. ${ }^{4}$ Department of Applied Physics and Electronics, Thermochemical Energy Conversion Laboratory, Umeå University, Umeå, Sweden. ${ }^{5}$ MRC-PHE Centre for Environment and Health, School of Biomedical Sciences, King's College London, London, UK. 'BHF/University Centre for Cardiovascular Science, University of Edinburgh, Edinburgh, UK.

Received: 10 December 2013 Accepted: 5 March 2014 Published: 13 March 2014

\section{References}

1. Dockery DW, Pope CA III, Xu X, Spengler JD, Ware JH, Fay ME, Ferris BG Jr, Speizer FE: An association between air pollution and mortality in six U.S cities. N Engl J Med 1993, 329(24):1753-1759.

2. Laden F, Schwartz J, Speizer FE, Dockery DW: Reduction in fine particulate air pollution and mortality: extended follow-up of the harvard six cities study. Am J Respir Crit Care Med 2006, 173(6):667-672.

3. Pope CA III: Mortality effects of longer term exposures to fine particulate air pollution: review of recent epidemiological evidence. Inhal Toxicol 2007, 19(Suppl 1):33-38.

4. Jerrett M, Burnett RT, Pope CA III, Ito K, Thurston G, Krewski D, Shi Y, Calle E, Thun M: Long-term ozone exposure and mortality. N Engl I Med 2009, 360(11):1085-1095.

5. Jerrett M, Shankardass K, Berhane K, Gauderman WJ, Kunzli N, Avol E, Gilliland F, Lurmann F, Molitor JN, Molitor JT, Thomas DC, Peters J, McConnell R: Traffic-related air pollution and asthma onset in children: a prospective cohort study with individual exposure measurement. Environ Health Perspect 2008, 116(10):1433-1438.

6. McCreanor J, Cullinan P, Nieuwenhuiisen MJ, Stewart-Evans J, Malliarou E, Jarup L, Harrington R, Svartengren M, Han IK, Ohman-Strickland P, Chung $\mathrm{KF}$, Zhang J: Respiratory effects of exposure to diesel traffic in persons with asthma. N Engl J Med 2007, 357(23):2348-2358. 
7. Peters A, Dockery DW, Muller JE, Mittleman MA: Increased particulate air pollution and the triggering of myocardial infarction. Circulation 2001, 103(23):2810-2815.

8. Peters A, von Klot S, Heier M, Trentinaglia I, Hormann A, Wichmann HE, Lowel H: Exposure to traffic and the onset of myocardial infarction. N Engl J Med 2004 351(17):1721-1730.

9. Lanki T, Hoek G, Timonen KL, Peters A, Tiittanen P, Vanninen E, Pekkanen J: Hourly variation in fine particle exposure is associated with transiently increased risk of ST segment depression. Occup Environ Med 2008, 65(11):782-786.

10. Langrish JP, Bosson J, Unosson J, Muala A, Newby DE, Mills NL, Blomberg A, Sandstrom T: Cardiovascular effects of particulate air pollution exposure: time course and underlying mechanisms. J Intern Med 2012, 272(3):224-239.

11. Zheng M, Cass GR, Ke L, Wang F, Schauer JJ, Edgerton ES, Russell AG: Source apportionment of daily fine particulate matter at Jefferson Street, Atlanta, GA, during summer and winter. J Air Waste Manag Assoc 2007, 57(2):228-242.

12. Salvi S, Blomberg A, Rudell B, Kelly F, Sandstrom T, Holgate ST, Frew A: Acute inflammatory responses in the airways and peripheral blood after short-term exposure to diesel exhaust in healthy human volunteers. Am J Respir Crit Care Med 1999, 159(3):702-709.

13. Salvi SS, Nordenhall C, Blomberg A, Rudell B, Pourazar J, Kelly FJ, Wilson S, Sandstrom T, Holgate ST, Frew AJ: Acute exposure to diesel exhaust increases IL-8 and GRO-alpha production in healthy human airways. Am J Respir Crit Care Med 2000, 161(2 Pt 1):550-557.

14. Pourazar J, Mudway IS, Samet JM, Helleday R, Blomberg A, Wilson SJ, Frew AJ, Kelly FJ, Sandstrom T: Diesel exhaust activates redox-sensitive transcription factors and kinases in human airways. Am J Physiol Lung Cell Mol Physiol 2005, 289(5):L724-L730.

15. Mills NL, Tornqvist H, Robinson SD, Gonzalez M, Darnley K, MacNee W, Boon NA, Donaldson K, Blomberg A, Sandstrom T, Newby DE: Diesel exhaust inhalation causes vascular dysfunction and impaired endogenous fibrinolysis. Circulation 2005, 112(25):3930-3936.

16. Lucking AJ, Lundback M, Mills NL, Faratian D, Barath SL, Pourazar J, Cassee FR, Donaldson K, Boon NA, Badimon JJ, Sandstrom T, Blomberg A, Newby DE: Diesel exhaust inhalation increases thrombus formation in man. Eur Heart J 2008, 29(24):3043-3051.

17. Lundback M, Mills NL, Lucking A, Barath S, Donaldson K, Newby DE, Sandstrom T, Blomberg A: Experimental exposure to diesel exhaust increases arterial stiffness in man. Part Fibre Toxicol 2009, 6:7

18. Lucking AJ, Lundback M, Barath SL, Mills NL, Sidhu MK, Langrish JP, Boon NA, Pourazar J, Badimon JJ, Gerlofs-Nijland ME, Cassee FR, Boman C, Donaldson K, Sandstrom T, Newby DE, Blomberg A: Particle traps prevent adverse vascular and prothrombotic effects of diesel engine exhaust inhalation in men. Circulation 2011, 123(16):1721-1728.

19. Lim SS, Vos T, Flaxman AD, Danaei G, Shibuya K, Adair-Rohani H, Amann M, Anderson HR, Andrews KG, Aryee M, Atkinson C, Bacchus LJ, Bahalim AN, Balakrishnan K, Balmes J, Barker-Collo S, Baxter A, Bell ML, Blore JD, Blyth F, Bonner C, Borges G, Bourne R, Boussinesq M, Brauer M, Brooks P, Bruce NG Brunekreef B, Bryan-Hancock C, Bucello C, et al: A comparative risk assessment of burden of disease and injury attributable to 67 risk factors and risk factor clusters in 21 regions, 1990-2010: a systematic analysis for the Global Burden of Disease Study 2010. Lancet 2012, 380(9859):2224-2260.

20. Brook RD, Rajagopalan S, Pope CA III, Brook JR, Bhatnagar A, Diez-Roux AV, Holguin F, Hong Y, Luepker RV, Mittleman MA, Peters A, Siscovick D, Smith SC Jr, Whitsel L, Kaufman JD: Particulate matter air pollution and cardiovascular disease: an update to the scientific statement from the American Heart Association. Circulation 2010, 121(21):2331-2378.

21. Smith-Sivertsen T, Diaz E, Pope D, Lie RT, Diaz A, McCracken J, Bakke P, Arana $B$, Smith KR, Bruce N: Effect of reducing indoor air pollution on women's respiratory symptoms and lung function: the RESPIRE randomized trial, Guatemala. Am J Epidemiol 2009, 170(2):211-220.

22. Clancy L, Goodman P, Sinclair H, Dockery DW: Effect of air-pollution control on death rates in Dublin, Ireland: an intervention study. Lancet 2002, 360(9341):1210-1214.

23. Thurston GD, Bekkedal MY, Roberts EM, Ito K, Pope CA III, Glenn BS, Ozkaynak H, Utell MJ: Use of health information in air pollution health research: past successes and emerging needs. J Expo Sci Environ Epidemiol 2009, 19(1):45-58.

24. Meyers DG, Neuberger JS, He J: Cardiovascular effect of bans on smoking in public places: a systematic review and meta-analysis. J Am Coll Cardiol 2009, 54(14):1249-1255.
25. Langrish JP, Li X, Wang S, Lee MM, Barnes GD, Miller MR, Cassee FR, Boon NA, Donaldson K, Li J, Li L, Mills NL, Newby DE, Jiang L: Reducing personal exposure to particulate air pollution improves cardiovascular health in patients with coronary heart disease. Environ Health Perspect 2011, 120(3):367-372.

26. Langrish JP, Mills NL, Chan JK, Leseman DL, Aitken RJ, Fokkens PH, Cassee FR, Li J, Donaldson K, Newby DE, Jiang L: Beneficial cardiovascular effects of reducing exposure to particulate air pollution with a simple facemask. Part Fibre Toxicol 2009, 6:8.

27. Zuurbier $M$, Hoek $G$, Oldenwening $M$, Lenters $V$, Meliefste $K$, van den Hazel $\mathrm{P}$, Brunekreef $\mathrm{B}$ : Commuters' exposure to particulate matter air pollution is affected by mode of transport, fuel type, and route. Environ Health Perspect 2010, 118(6):783-789.

28. Rank J, Folke J, Jespersen PH: Differences in cyclists and car drivers exposure to air pollution from traffic in the city of Copenhagen. Sci Total Environ 2001, 279(1-3):131-136.

29. Briggs DJ, de Hoogh K, Morris C, Gulliver J: Effects of travel mode on exposures to particulate air pollution. Environ Int 2008, 34(1):12-22

30. Brauner EV, Forchhammer L, Moller P, Barregard L, Gunnarsen L, Afshari A Wahlin P, Glasius M, Dragsted LO, Basu S, Raaschou-Nielsen O, Loft S: Indoor particles affect vascular function in the aged: an air filtration-based intervention study. Am J Respir Crit Care Med 2008, 177(4):419-425.

31. Rudell B, Wass U, Horstedt P, Levin JO, Lindahl R, Rannug U, Sunesson AL, Ostberg Y, Sandstrom T: Efficiency of automotive cabin air filters to reduce acute health effects of diesel exhaust in human subjects. Occup Environ Med 1999, 56(4):222-231.

32. Behndig AF, Mudway IS, Brown JL, Stenfors N, Helleday R, Duggan ST, Wilson SJ, Boman C, Cassee FR, Frew AJ, Kelly FJ, Sandstrom T, Blomberg A: Airway antioxidant and inflammatory responses to diesel exhaust exposure in healthy humans. Eur Respir J 2006, 27(2):359-365.

33. Barath S, Mills NL, Lundback M, Tornqvist H, Lucking AJ, Langrish JP, Soderberg S, Boman C, Westerholm R, Londahl J, Donaldson K, Mudway IS, Sandstrom T, Newby DE, Blomberg A: Impaired vascular function after exposure to diesel exhaust generated at urban transient running conditions. Part Fibre Toxicol 2010, 7:19.

34. Rissler J, Swietlicki E, Bengtsson A, Boman C, Pagels J, Sandstrom T, Blomberg A, Londahl J: Experimental determination of deposition of diesel exhaust particles in the human respiratory tract. J Aerosol Sci 2012, 48:18-33.

35. Rudell B, Ledin MC, Hammarstrom U, Stjernberg N, Lundback B, Sandstrom $\mathrm{T}$ : Effects on symptoms and lung function in humans experimentally exposed to diesel exhaust. Occup Environ Med 1996, 53(10):658-662.

36. Steenhof M, Gosens I, Strak M, Godri KJ, Hoek G, Cassee FR, Mudway IS, Kelly FJ, Harrison RM, Lebret E, Brunekreef B, Janssen NA, Pieters RH: In vitro toxicity of particulate matter (PM) collected at different sites in the Netherlands is associated with PM composition, size fraction and oxidative potential-the RAPTES project. Part Fibre Toxicol 2011, 8:26.

37. Godri KJ, Harrison RM, Evans T, Baker T, Dunster C, Mudway IS, Kelly FJ: Increased oxidative burden associated with traffic component of ambient particulate matter at roadside and urban background schools sites in London. PLoS One 2011, 6(7):e21961.

38. Peters A, von Klot S, Heier M, Trentinaglia I, Cyrys J, Hormann A, Hauptmann M, Wichmann HE, Lowel H: Particulate air pollution and nonfatal cardiac events: part I: air pollution, personal activities, and onset of myocardial infarction in a case-crossover study. Res Rep Health Eff Inst 2005(124):1-66. discussion 67-82, 141-148.

39. Rudell B, Blomberg A, Helleday R, Ledin MC, Lundback B, Stjernberg N, Horstedt $P$, Sandstrom T: Bronchoalveolar inflammation after exposure to diesel exhaust: comparison between unfiltered and particle trap filtered exhaust. Occup Environ Med 1999, 56(8):527-534.

40. Schlesinger RB, Kunzli N, Hidy GM, Gotschi T, Jerrett M: The health relevance of ambient particulate matter characteristics: coherence of toxicological and epidemiological inferences. Inhal Toxicol 2006, 18(2):95-125.

41. Nel A: Atmosphere: air pollution-related illness: effects of particles. Science 2005, 308(5723):804-806.

42. Pourazar J, Frew AJ, Blomberg A, Helleday R, Kelly FJ, Wilson S, Sandstrom T: Diesel exhaust exposure enhances the expression of IL-13 in the bronchial epithelium of healthy subjects. Respir Med 2004, 98(9):821-825.

43. Pourazar J, Blomberg A, Kelly FJ, Davies DE, Wilson SJ, Holgate ST, Sandstrom T: Diesel exhaust increases EGFR and phosphorylated Cterminal Tyr 1173 in the bronchial epithelium. Part Fibre Toxicol 2008, 5:8. 
44. Bosson J, Blomberg A, Pourazar J, Mudway IS, Frew AJ, Kelly FJ, Sandstrom T: Early suppression of NFkappaB and IL-8 in bronchial epithelium after ozone exposure in healthy human subjects. Inhal Toxicol 2009, 21(11):913-919.

45. Mudway IS, Stenfors N, Duggan ST, Roxborough H, Zielinski H, Marklund SL, Blomberg A, Frew AJ, Sandstrom T, Kelly FJ: An in vitro and in vivo investigation of the effects of diesel exhaust on human airway lining fluid antioxidants. Arch Biochem Biophys 2004, 423(1):200-212.

46. Kelly F, Anderson HR, Armstrong B, Atkinson R, Barratt B, Beevers S, Derwent D, Green D, Mudway I, Wilkinson P: The impact of the congestion charging scheme on air quality in London: part 2: analysis of the oxidative potential of particulate matter. Res Rep Health Eff Inst 2011, 155:73-144.

47. Mills NL, Tornqvist H, Gonzalez MC, Vink E, Robinson SD, Soderberg S, Boon NA, Donaldson K, Sandstrom T, Blomberg A, Newby DE: Ischemic and thrombotic effects of dilute diesel-exhaust inhalation in men with coronary heart disease. N Engl J Med 2007, 357(11):1075-1082.

48. Tornqvist H, Mills NL, Gonzalez M, Miller MR, Robinson SD, Megson IL, Macnee W, Donaldson K, Soderberg S, Newby DE, Sandstrom T, Blomberg A: Persistent endothelial dysfunction in humans after diesel exhaust inhalation. Am J Respir Crit Care Med 2007, 176(4):395-400.

doi:10.1186/1476-069X-13-16

Cite this article as: Muala et al: Assessment of the capacity of vehicle cabin air inlet filters to reduce diesel exhaust-induced symptoms in human volunteers. Environmental Health 2014 13:16.

\section{Submit your next manuscript to BioMed Central and take full advantage of:}

- Convenient online submission

- Thorough peer review

- No space constraints or color figure charges

- Immediate publication on acceptance

- Inclusion in PubMed, CAS, Scopus and Google Scholar

- Research which is freely available for redistribution

Submit your manuscript at www.biomedcentral.com/submit

C Biomed Central 